$\underset{\text { clinical }}{\text { nephron }}$

Practice
Nephron 2015;131:252-254

DOI: $10.1159 / 000437312$
Received: May 21, 2015

Accepted after revision: June 28, 2015

Published online: December 17, 2015

\title{
Urine Output Assessment as a Clinical Quality Measure
}

\author{
Etienne Macedo \\ Nephrology Department, University of São Paulo School of Medicine, São Paulo, Brazil
}

\section{Key Words \\ Acute kidney injury · Oliguria · Urine output}

\begin{abstract}
Urine output (UO) is a relevant marker of kidney function and an independent marker of serum creatinine. Although oliguria can be the result of transitory changes in volume status or due to external influences, such as drug administration, $\mathrm{UO}$ is currently included as a criterion to diagnose and stage acute kidney injury (AKI). In clinical practice, the potential of earlier alert of kidney injury with frequent assessment of UO can help patient screening and risk assessment. In this review, we will discuss recent studies applying UO for AKI diagnosis and prognostication and propose methods to assess UO and improve quality of care.

(c) 2015 S. Karger AG, Basel
\end{abstract}

\section{Introduction}

Since the development of the Risk, Injury, Failure, Loss of kidney function and End-stage kidney disease (RIFLE) criteria and the following Acute Kidney Injury Network (AKIN) and Kidney Disease Improving Global Outcomes (KDIGO) classification system, urine output (UO) has proven to be a sensitive and early marker for acute kidney injury (AKI), which is associated with adverse outcomes in ICU patients. Oliguria is a frequent event in ICU pa- tients and the final pathway for several injuries to renal parenchyma. Since UO has been included as a criterion to diagnose and stage AKI, an increasing number of studies have proven that decrease in UO, even without serum creatinine ( $\mathrm{sCr}$ ) elevation, is a specific marker of AKI that correlates with outcomes. A major barrier to the application of the UO criterion is that accurate hourly UO measurements have been difficult to obtain. Urine flow measurements are time-consuming, as urine meters require manipulation, visual assessment and manual data recording. In most ICUs, nurses empty the collection bag every $6 \mathrm{~h}$. These difficulties in measuring, monitoring and accurately recording UO have resulted in a lack of a standardized approach to assess changes in UO and the identification of episodes of oliguria.

\section{Timeframe for Oliguria Assessment}

For retrospective evaluations and prospective epidemiologic studies, the assessment of total urine volume over longer time intervals simplifies the application of the criteria, since most hospitals do not have digital monitors to record UO hourly. The sensitivity and specificity of the

Contribution from the AKI \& CRRT 2015 Symposium at the 20th International Conference on Advances in Critical Care Nephrology, Manchester Grand Hyatt, San Diego, Calif., USA, February 17-20, 2015

\section{KARGER 125}

(c) 2015 S. Karger AG, Basel

$1660-8151 / 15 / 1314-0252 \$ 39.50 / 0$

E-Mail karger@karger.com

www.karger.com/nef
Dr. Etienne Macedo

Nephrology Department, University of São Paulo School of Medicine

Av. Dr. Enéas de Carvalho Aguiar, 255

São Paulo, SP 05403-000 (Brazil)

E-Mail etimacedo@usp.br 
strictest interpretation of the $\mathrm{AKIN}_{\mathrm{UO}}$ criterion, requiring the urine volume to be $<0.5 \mathrm{ml} / \mathrm{kg}$ every hour during consecutive $6 \mathrm{~h}$, was compared to the UO criterion assessed over a $6 \mathrm{~h}$ interval [3]. Macedo et al. [3] evaluated the UO over fixed blocks of $6 \mathrm{~h}$, where oliguria was defined as a volume $<3 \mathrm{ml} / \mathrm{kg}$ during consecutive $6 \mathrm{~h}$. The fixed blocks matched the nurse's shift, facilitating the application. They demonstrated that assessing the urine volume in a 6-hour block resulted in a higher sensitivity with lower specificity compared to the current stricter criteria that require a volume $<0.5 \mathrm{ml} / \mathrm{kg}$ every hour during consecutive $6 \mathrm{~h}$.

Balancing the practicality of using longer time intervals against ascertaining urine flow every hour to diagnose oliguria is challenging. The assessment of $\mathrm{UO}$ in blocks of $6 \mathrm{~h}$ could help the implementation of quality measurement protocols in wards and post-operative settings. It could facilitate the use of alert systems to provide an earlier sign of impeding kidney dysfunction. However, in critically ill patients, the hourly information on urine volume, with more frequent observations of the parameter, could allow an earlier detection of AKI. Prowle et al. [4] conducted a multinational study to evaluate the relationship of short episodes of oliguria, $U O<0.5 \mathrm{ml} / \mathrm{kg} / \mathrm{h}$, with subsequent development of AKI. They found that oliguria for $>1$ h was significantly associated with AKI by $\mathrm{sCr}$ the next day. The presence of oliguria for $4 \mathrm{~h}$ or more provided the best discrimination to detect AKI.

\section{Earlier AKI Diagnosis Based on UO}

A key issue is whether UO would provide an earlier indication of renal dysfunction than sCr. Since measurements of sCr and UO are not done at the same time intervals, it is difficult to make a fair comparison. Macedo et al. [13] showed that the time frame to reach AKI diagnosis by the UO criterion was shorter than it was by sCr criterion. However, the difference was not significant when analyzing patients with sCr available every $12 \mathrm{~h}$. This fact emphasizes the importance of timed interval samples determining the accuracy of a biomarker. Wlodzimirow et al. [5] performed an observational study with hourly assessment of UO. Discarding the RIFLE $\mathrm{UO}_{\mathrm{U}}$ criteria for AKI diagnosis significantly underestimated the presence and severity of AKI on admission and during the first ICU week and significantly delayed the diagnosis of AKI. In $53 \%$ of the patients, AKI would have been diagnosed at least 1 day earlier if the RIFLE $_{U O}$ criteria had been applied.

UO Assessment

\section{UO Criterion and Outcomes}

Studies applying the UO criterion in addition to the sCr criterion have shown an increase in number of patients diagnosed with AKI, increasing the sensitivity of the diagnostic criteria. However, the effect of adding the $\mathrm{UO}$ criterion to $\mathrm{sCr}$ to predict mortality has shown discordant results [6-10]. Joannidis et al. [6], used a modified form of the $\mathrm{AKIN}_{\mathrm{UO}}$ criterion, classifying patients with $<0.5 \mathrm{ml} / \mathrm{kg} / \mathrm{h}$ in $24 \mathrm{~h}$ as RIFLE injury. The mortality rate observed for each degree of AKI based on the worst UO alone was lower than the same stage of injury characterized by sCr. The classification of AKI using only the worst $\mathrm{sCr}$ resulted in higher mortality rates at each stage as compared to categorization by either UO or the composite criteria. Haase et al. [7] classified patients by UO independent of the sCr criteria during the first $48 \mathrm{~h}$ of ICU stay. AKI classified by the UO criterion led to a lower predictive value for in-hospital mortality compared to the $\mathrm{sCr}$ criterion. A systematic review, including studies using the modified UO criterion, indicated that the relative risk for death using both $\mathrm{sCr}$ and $\mathrm{UO}$ criteria tend to be lower compared to that of exclusively using the $\mathrm{sCr}$ criterion.

\section{Refining the UO Definition}

The use of both criteria, sCr and UO, leads to a considerable increase in the incidence along with a decrease in associated mortality. Studies have showed that up to $80 \%$ of ICU patients can be diagnosed with AKI when applying the full KDIGO criteria $[5,11]$. However, spontaneous resolution or prompt response to treatment can occur, especially in those patients classified exclusively by the UO criterion. Studies applying both criteria have shown that as much as $40 \%$ of patients classified as AKI by the UO criterion will not develop AKI by the $\mathrm{sCr}$ criterion $[3,5,12]$. In addition, patients classified solely by the UO criterion are mostly RIFLE-R or stage 1 showing higher rates of recovery. Recently, some studies have tried to evaluate if the cutoff value and duration of oliguria could be improved to better match the outcomes associated with sCr elevation. Md Ralib et al. [10] analyzed hourly UO in collection intervals between 1 and $12 \mathrm{~h}$ in ICU patients. A stricter UO threshold of $0.3 \mathrm{ml} / \mathrm{kg} / \mathrm{h}$ over $6 \mathrm{~h}$ was best associated with mortality and dialysis and was independently predictive of both hospital mortality and 1-year mortality. This result suggests that the current AKI-UO definition could be too liberal and as a result in- 
clude patients with lower risk of progression of AKI, need for RRT or death.

Kellum et al. [13] classified ICU patients by sCr and/ or UO according to KDIGO staging criteria. In contrast to the study by Md Ralib et al. [10], Kellum et al. [13] evaluated the effect of $\mathrm{UO}$ and $\mathrm{sCr}$ together in a cohort in which 23,866 (74.5\%) patients developed AKI. For the patients (37.1\%) manifesting AKI by only one parameter, hospital mortality was $18 \%$ and increased to $30 \%$ in patients reaching stage 3 by one criterion and stage 1 criteria by another. Patients who met stage 3 criteria by both UO and $\mathrm{sCr}$ had the highest mortality rate, $51.1 \%$. These findings confirm that even small increments in sCr (stage 1) dramatically increase mortality in oliguric patients and emphasize the importance of both $\mathrm{UO}$ and SC in the assessment of AKI.

\section{UO Assessment as a Quality Paradigm}

It is important to recognize all the challenges in assessing UO in the different clinical settings. The non-availability of automatic urine meters, the balance of urinary catheters placement and risk of infection are often impeding factors in applying the more strict UO criteria definition. Despite these difficulties, the results of recent studies establish the absolute necessity for UO assessment in patients for diagnosing and staging AKI. Applying the UO criteria can increase the sensitivity and specificity of the AKIN classification system, as oliguric patients without
sCr change have an increased mortality, dialysis requirement and longer length of ICU stay than non-AKI patients. Applying the AKIN classification system without the urine criteria significantly underscores the incidence and grade of AKI and significantly delays the diagnosis of AKI.

\section{Conclusion}

The implementation of strategies to assess UO in all hospital settings should be prioritized. Criterion and time frame for AKI screening and diagnosis can be adjusted according to the patients' setting and risk of AKI. Triage, monitoring and prognostication based on early detection of decrease in UO is fundamental not only for avoiding and preventing AKI, but also for tracking volume overload and assessing response to therapy. It is possible that different sensitivity and specificity thresholds could be applicable based on the population being assessed and the purpose of the assessment. Further application of the criterion in different settings and patient population will provide information to further refine the parameters of UO to triage, monitor and define treatment of AKI based on the UO criterion.

\section{Disclosure Statement}

The author has no conflicts of interest to declare.

\section{References}

1 Silvester W, Bellomo R, Cole L: Epidemiology, management, and outcome of severe acute renal failure of critical illness in Australia. Crit Care Med 2001;29:1910-1915.

-2 Brivet FG, Kleinknecht DJ, Loirat P, Landais PJ: Acute renal failure in intensive care units causes, outcome, and prognostic factors of hospital mortality; a prospective, multicenter study. French Study Group on Acute Renal Failure. Crit Care Med 1996;24:192-198.

-3 Macedo E, Malhotra R, Bouchard J, Wynn SK, Mehta RL: Oliguria is an early predictor of higher mortality in critically ill patients. Kidney Int 2011;80:760-767.

-4 Prowle JR, Liu YL, Licari E, Bagshaw SM, Egi M, Haase M, et al: Oliguria as predictive biomarker of acute kidney injury in critically ill patients. Crit Care 2011;15:R172.

$\checkmark 5$ Wlodzimirow KA, Abu-Hanna A, Slabbekoorn M, Chamuleau RA, Schultz MJ, Bouman CS: A comparison of RIFLE with and without urine output criteria for acute kidney injury in critically ill patients. Crit Care 2012; 16:R200.

6 Joannidis M, Metnitz B, Bauer P, Schusterschitz N, Moreno R, Druml W, et al: Acute kidney injury in critically ill patients classified by AKIN versus RIFLE using the SAPS 3 database. Intensive Care Med 2009;35:1692-1702.

7 Haase M, Bellomo R, Matalanis G, Calzavacca P, Dragun D, Haase-Fielitz A: A comparison of the RIFLE and Acute Kidney Injury Network classifications for cardiac surgery-associated acute kidney injury: a prospective cohort study. J Thorac Cardiovasc Surg 2009; 138:1370-1376.

8 Hoste EA, Kellum JA: RIFLE criteria provide robust assessment of kidney dysfunction and correlate with hospital mortality. Crit Care Med 2006;34:2016-2017.

\9 Cruz DN, Bolgan I, Perazella MA, Bonello M, de Cal M, Corradi V, et al: North East Italian
Prospective Hospital Renal Outcome Survey on Acute Kidney Injury (NEiPHROS-AKI): targeting the problem with the RIFLE criteria. Clin J Am Soc Nephrol 2007;2:418-425.

10 Md Ralib A, Pickering JW, Shaw GM, Endre $\mathrm{ZH}$ : The urine output definition of acute kidney injury is too liberal. Crit Care 2013;17:R112.

-11 Ali T, Khan I, Simpson W, Prescott G, Townend J, Smith W, et al: Incidence and outcomes in acute kidney injury: a comprehensive population-based study. J Am Soc Nephrol 2007;18:1292-1298.

$\checkmark 12$ Macedo E, Malhotra R, Claure-Del Granado R, Fedullo P, Mehta RL: Defining urine output criterion for acute kidney injury in critically ill patients. Nephrol Dial Transplant 2011;26:509-515.

13 Kellum JA, Sileanu FE, Murugan R, Lucko N, Shaw AD, Clermont G: Classifying AKI by urine output versus serum creatinine level. J Am Soc Nephrol 2015;26:2231-2238. 